Terbit online pada laman web jurnal : http://e-journal.sastra-unes.com/index.php/JIPS

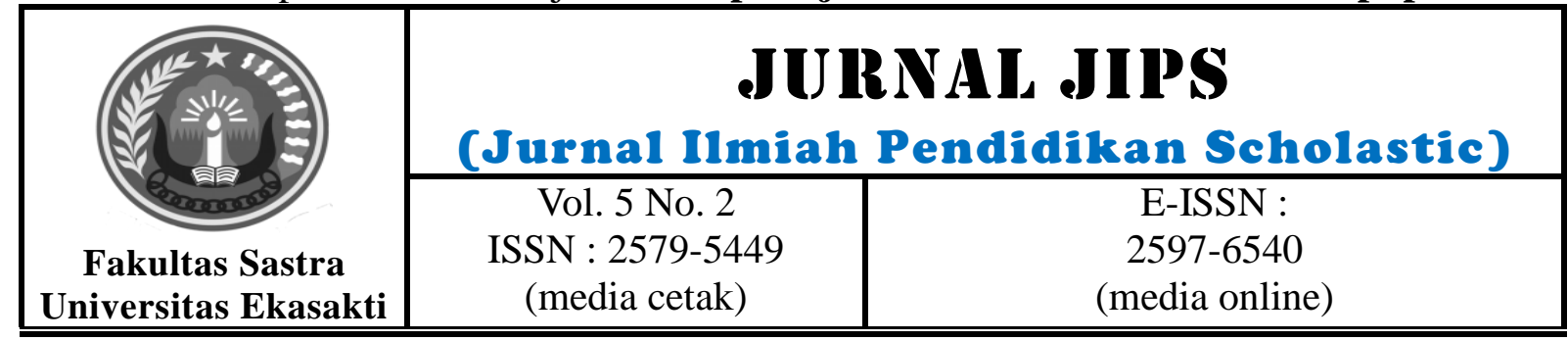

\title{
IMPLEMENTASI PROGRAM GERAKAN INDONESIA SADAR ADMINISTRASI KEPENDUDUKAN (GISA) DI DESA LUMINDAI KOTA SAWAHLUNTO
}

\author{
Devi Anita \\ Sekolah Tinggi Ilmu Administrasi (STIA) Adabiah Padang \\ devianita68@gmail.com
}

\begin{abstract}
\end{abstract}
Researchers who focus on research at the Lumindai Village Office, Sawahlunto City. With problems: in recent years one of the problems in terms of population is related to administrative problems. One of the triggers for this is the lack of public awareness of administrative order. In an effort to overcome this problem, the government created the Indonesian Awareness Administrative Movement (GISA) program. The purpose of this study is to determine the extent of the implementation of the GISA Program in Lumindai Village, Sawahlunto City. In this study, a study was conducted on the Implementation of the Indonesian Population Administration Awareness Movement Program (GISA) in Lumdai Village, Sawahlunto City. Using Implementation Theory according to George C. Edward III in Widodo (2011:107), an analysis is carried out regarding things that affect the success and failure of policy implementation, namely communication, resources, disposition, and structure factors. These factors were discussed through direct interviews with village officials as the main actors in the GISA program, joint interviews and through direct observation.

The results showed that there were several obstacles in the implementation of the GISA program in Lumindai Village, namely the problem of human resources, lack of socialization to the community, the location of the village which was far from the population and civil registration office and the lack of personnel to serve the population administration.

The conclusion is that the implementation of the GISA program in Lumindai Village, Sawahlunto City is still not running optimally. Improvements are needed, both in terms of employees and from the community itself, government efforts are needed to increase public awareness, in order to achieve the objectives of this GISA program, consideration is needed from the Lumindai Village leadership for additional staff so that in serving the community more optimally and the need for discussion about SOPs in order to run well.

Keywords: Administration, Implementation, GISA,

Jurnal JIPS (Jurnal Ilmiah Pendidikan Scholastic ) Vol. 5 No. 2 (2021) ISSN : 2579-5449

This work is licensed under a Creative Commons Attribution-NonCommercial 4.0 International License. 


\section{Abstrak}

Peneliti memfokuskan penelitian di Kantor Desa Lumindai Kota Sawahlunto. Dengan identifikasi masalah: beberapa tahun terakhir salah satu permasalahan dalam hal kependudukan adalah terkait masalah administratif. Salah satu pemicu hal ini adalah kurangnya kesadaran masyarakat akan tertib administratif. Dalam upaya mengatasi permasalahan ini pemerintah membuat program Gerakan Indonesia Sadar Administratif (GISA).

Tujuan penelitian ini yaitu untuk mengetahui sejauh mana implementasi Program GISA di Desa Lumindai Kota Sawahlunto. Dalam penelitian ini dilakukan studi mengenai Implementasi Program Gerakan Indonesia Sadar Administrasi Kependudukan (GISA) di Desa Lumindai Kota Sawahlunto. Menggunakan teori Implementasi menurut George C. Edward III dalam Widodo (2011:107), dilakukan analisis terkait hal yang mempengaruhi keberhasilan dan kegagalan implementasi kebijakan yaitu faktor komunikasi, sumber daya, disposisi, dan struktur birokrasi. Faktor-faktor implementasi ditinjau melalui wawancara langsung bersama perangkat desa sebagai pelaku utama dalam program GISA, wawancara bersama masyarakat serta melalui pengamatan langsung.

Hasil penelitian menunjukkan bahwa terdapat beberapa kendala dalam implementasi program GISA di Desa Lumindai, yaitu terkait masalah sumber daya manusia, kurangnya sosialisasi kepada masyarakat, lokasi desa yang jauh dari kantor kependudukan dan pencatatan sipil dan kekurangan personil untuk melayani administrasi kependudukan tersebut.

Kesimpulannya bahwa implementasi program GISA di Desa Lumindai Kota Sawahlunto masih belum berlangsung secara maksimal. Di sarankan perlu adanya perbaikan SDM, baik dari segi pegawai maupun dari masyarakat itu sendiri, diperlukan adanya upaya pemerintah untuk meningkatkan kesadaran masyarakat, agar tercapai tujuan dari program GISA ini, diperlukannya pertimbangan dari pimpinan Desa Lumindai untuk penambahan staf agar dalam melayani masyarakat lebih maksimal dan perlu adanya pembahasan mengenai SOP agar bisa berjalan dengan baik.

Kata kunci: Administrasi, Implementasi, GISA,

(C) 2021Jurnal JIPS

\section{INTRODUCTION}

Administrasi Kependudukan adalah rangkaian kegiatan penataan dan penertiban dalam penerbitan dokumen dan data kependudukan melalui pendaftaran penduduk, pencatatan sipil, pengelolaan informasi penduduk pendayagunaan hasilnya untuk pelayanan publik dan pembangunan sektor lain.

Indonesia sebagai negara kepulauan mempunyai persebaran penduduk yang tidak merata, faktor pertumbuhan penduduk yang besar serta rendahnya kualitas penduduk juga menjadi suatu permasalahan yang berkaitan dengan kependudukan. Dokumen Kependudukan adalah dokumen resmi yang diterbitkan oleh instansi pelaksana yang mempunyai dokumen kekuatan hukum sebagai alat bukti otentik yang dihasilkan dari pelayanan pendaftaran penduduk dan pencatatan sipil. (UU Nomor 24 Tahun 2013).
Maka dari itu pentingnya kesadaran public sebagai salah satu faktor pendukung dalam menjalankan program pemerintah yaitu Program Gerakan Indonesia Sadar Adminduk (GISA). Program ini di keluarkan di tahun 2018, yang diatur dalam Permendagri Nomor 507/837/SJ Tentang Gerakan Indonesia Sadar Administrasi Kependudukan (GISA) dilaunching oleh Menteri Dalam Negeri Tjahyo Kumolo bersama Dirjen Dukcapil Zudan Arif Fakrulloh.

Program GISA bertujuan untuk meningkatkan kesadaran masyarakat terutama di bidang administrasi kependudukan menuju masyarakat yang tertib dan sadar administrasi. Target dari Program GISA sendiri adalah masyarakat, petugas pelayanan administrasi kependudukan, pemerintah dan swasta serta 
diterapkan dari tingkat desa, kecamatan, kota/ kabupaten, provinsi maupun ditingkat nasional.

Program utama dari GISA ini adalah; 1) kesadaran akan kepemilikan dokumen kependudukan dimana setiap penduduk diwajibkan memiliki setiap dokumen kependudukan yang dikeluarkan oleh Dinas Kependudukan dan Pencatatan Sipil supaya pencapaian target kinerja sesuai target nasional; 2) sadar akan pemutakhiran data penduduk dimana kesadaran setiap penduduk akan melaporkan setiap terjadi perubahan peristiwa kependudukan; 3) kesadaran pemanfaatan data kependudukan sebagai satu-satunya data yang digunakan untuk semua keperluan; 4) program sadar melayani kependudukan menuju masyarakat yang bahagia dimana aparatur dapat memberikan kenyamanan dalam pelayanan dan bisa membuat inovasi pelayanan administrasi kependudukan menjadi lebih efektif dan efisien.

Salah satu desa yang ada di Kota Sawahlunto yang melaksanakan program GISA adalah Desa Lumindai. Desa Lumindai merupakan desa penduduk terbanyak se-Kecamatan Barangin Kota Sawahlunto, dengan jumlah penduduk \pm 2.839 Jiwa dengan jumlah Kepala Keluarga \pm 808 KK. Dari sekian banyak penduduk namun faktanya masih banyak yang belum melakukan upgrade Kartu Keluarga (KK), masih banyak terdapat penduduk Desa Lumindai yang belum memiliki dokumen Akta Kelahiran dan masih rendahnya kesadaran masyarakat untuk mengurus kepemilikan dokumen kependudukan. Hal ini menggambarkan bahwa kurangnya implementasi Program Gerakan Indonesia Sadar Administrasi Kependudukan (GISA) di Desa Lumindai. Hal ini dapat dilihat di Tabel 1.1 di bawah ini:

Tabel 1.1

Data Penduduk Yang Memiliki/

Tidak Memiliki Dokumen

\begin{tabular}{|c|c|c|c|}
\hline $\begin{array}{l}\mathbf{N} \\
\mathbf{O}\end{array}$ & URAIAN & $\begin{array}{c}\text { JUML } \\
\text { AH } \\
\text { ORAN } \\
\text { G } \\
\end{array}$ & $\begin{array}{l}\text { PERSEN } \\
\text { TASE }\end{array}$ \\
\hline 1 & $\begin{array}{l}\text { Yang Memiliki Akta } \\
\text { Kelahiran }\end{array}$ & 1671 & $58.86 \%$ \\
\hline 2 & $\begin{array}{lr}\text { Yang } & \text { Belum } \\
\text { Memiliki } & \text { Akta } \\
\text { Kelahiran } & \end{array}$ & 1168 & $41.14 \%$ \\
\hline
\end{tabular}

\begin{tabular}{|c|c|c|c|}
\hline 3 & $\begin{array}{l}\text { Yang } \\
\text { Memiliki KIA }\end{array}$ & 258 & $29.83 \%$ \\
\hline 4 & $\begin{array}{l}\text { Yang Belum } \\
\text { Memiliki KIA }\end{array}$ & 607 & $70.17 \%$ \\
\hline 5 & $\begin{array}{lr}\text { Yang } & \text { Sudah } \\
\text { Upgrade } & \text { Kartu } \\
\text { Keluarga } & \\
\end{array}$ & 501 & $62.00 \%$ \\
\hline 6 & $\begin{array}{lr}\text { Yang } & \text { Belum } \\
\text { Upgrade } & \text { Kartu } \\
\text { Keluarga } & \\
\end{array}$ & 307 & $38.00 \%$ \\
\hline 7 & $\begin{array}{l}\text { Yang Sudah } \\
\text { Memiliki KTP }\end{array}$ & 1855 & $93.97 \%$ \\
\hline 8 & $\begin{array}{l}\text { Yang Belum } \\
\text { Memiliki KTP }\end{array}$ & 119 & $6.03 \%$ \\
\hline
\end{tabular}

Sumber: DKB Semester I Tahun 2020

Berdasarkan pengamatan peneliti di lapangan, rendahnya implementasi program Gerakan Indonesia Sadar Administrasi Kependudukan di Desa Lumindai timbul dari berbagai faktor. Pertama dari faktor pemerintahan itu sendiri yaitu kurangnya sosialisasi mengenai program GISA tersebut sehingga kurangnya pemahaman masyarakat dalam menerima program tersebut karena minimnya sumber daya penduduk Desa Lumindai. Kemudian dari segi petugas registrasi di desa, yaitu kurangnya personil dalam melayani administrasi kependudukan. dan persyaratan yang akan diisi itu sangat banyak, sehingga terkadang menyebabkan bahan persyaratan masyarakat banyak menumpuk di desa.

Di samping itu, jarak antara dinas kependudukan dan pencatatan sipil dengan kantor desa yang sangat jauh sehingga bahan yang menumpuk hanya bisa diantar sekali dalam seminggu. Ini dapat menghambat perkembangan pengurusan administrasi kependudukan penduduk Desa Lumindai. Ada juga faktor masalah dari program itu sendiri yaitu ingin mencapai target dalam pembuatan akta kelahiran namun jika umur sudah melebihi dua bulan maka akan dikenakan denda admnistrasi. Mekanisme denda ini justru akan membuat masyarakat enggan mengurus dokumen tersebut, yang seharusnya jika ingin mencapai target pencapaian maka dalam mengurus dokumen tanpa dipungut biaya.

Terakhir faktor dari masyarakat itu sendiri, yaitu enggannya mengurus dokumen kependudukan dikarenakan ada beberapa alasan. Yang pertama karena ada beberapa masyarakat

Jurnal JIPS (Jurnal Ilmiah Pendidikan Scholastic ) Vol. 5 No. 2 (2021) ISSN : 2579-5449

This work is licensed under a Creative Commons Attribution-NonCommercial 4.0 International License. 
yang merasa kalau dokumen kependudukan tersebut tidak penting, karena mayoritas masyarakat Desa Lumindai itu petani/ pekebun. Ada sebagian lagi masyarakat enggan karena kekurangan persyaratan yang telah ditetapkan, sehingga menurunkan semangat dan kesadarannya dalam mengurus dokumen kependudukan. Kebanyakan masyarakat mengurus dokumen kependudukan itu jika dokumen tersebut diperlukan untuk esok hari

\section{RESEARCH METHOD}

Penelitian yang peneliti lakukan adalah penelitian dengan pendekatan kualitatif. Menurut Sugiyono (2009:15) metode penelitian kualitatif adalah suatu metode penelitian yang berlandaskan pada filsafat post-positivisme, digunakan untuk meneliti pada kondisi objek yang alamiah dimana peneliti adalah sebagi instrument kunci. Penelitian kualitatif bertumpu pada latar belakang alamiah secara holistic, memposisikan manusia sebagai alat penelitian, melakukan analisis data secara induktif, lebih mementingkan proses dari pada hasil serta hasil penelitian yang dilakukan disepakati oleh peneliti dan subjek penelitian.

Penentuan subjek penelitian dalam penelitian ini menggunakan teknik sampling. Menurut Sugiyono (2019:128) Teknik Sampling adalah teknik pengambilan sampel. Dalam penelitian ini teknik sampling yang dipakai adalah Purposive Sampling. Purposive Sampling adalah teknik pengambilan sampel dengan pertimbangan tertentu. Menurut Andi (2010:147) informan adalah orang yang diperkirakan menguasai dan

\section{RESULTS AND DISCUSSION}

1. Implementasi Program Gerakan Indonesia Sadar Administrasi Kependudukan (GISA) di Desa Lumindai Kota Sawahlunto

Implementasi merupakan suatu proses yang melibatkan sejumlah sumber yang termasuk manusia, dana, dan kemampuan organisasi yang dilakukan oleh pemerintah maupun swasta (Individu/ Kelompok). Proses tersebut dilakukan untuk mencapai tujuan yang telah ditetapkan maka baru diurus hari ini, sedangkan dalam mengurus dokumen kependudukan itu sudah punya Standar Operasional Pelayanan (SOP).

Beranjak dari permasalahan diatas maka penulis tertarik untuk melakukan penelitian tentang "IMPLEMENTASI PROGRAM GERAKAN INDONESIA SADAR ADMINISTRASI KEPENDUDUKAN (GISA) DI DESA LUMINDAI KOTA SAWAHLUNTO"

memahami data, informasi, ataupun fakta dari suatu objek penelitian.

Data infoman penelitian terlihat pada tabel 2.1 berikut ini:

Tabel 2.1

Informan Penelitian

\begin{tabular}{|c|l|c|}
\hline NO & \multicolumn{1}{|c|}{ SUMBER DATA } & JUMLAH \\
\hline 1 & Kepala Desa & 1 orang \\
\hline 2 & Sekretaris Desa & 1 orang \\
\hline 3 & Kasi Pemerintahan & 1 orang \\
\hline 4 & Petugas Registrasi & 1 orang \\
\hline 5 & Kepala Dusun & 5 orang \\
\hline 6 & Masyarakat & 5 orang \\
\hline & TOTAL & 14 Orang \\
\hline
\end{tabular}

\section{Teknik Pengumpulan Data}

Dalam penelitian ini jenis dan sumber data yang digunakan adalah:

\section{a. Data primer \\ Data Sekunder}

sebelumnya oleh pembuat kebijakan. Sebuah implementasi kebijakan yang melibatkan banyak organisasi dan tingkatan birokrasi dapat dilihat dari beberapa sudut pandang seperti pembuat kebijakan, pejabat-pejabat pelaksana dilapangan, dan sasaran kebijakan. Perlu disadari bahwa dalam melaksanakan implementasi suatu kebijakan tidak selalu berjalan seperti yang diharapkan. Banyak faktor yang dapat 
mempengaruhi keberhasilan suatu implementasi kebijakan.

Menurut George C. Edward III (2011:107) terdapat empat faktor yang berpengaruh terhadap implementasi kebijakan yaitu Faktor Komunikasi, Sumber Daya, Disposisi dan Struktur Birokrasi:

\section{a. Faktor Komunikasi (Communication)}

Komunikasi merupakan salah satu variabel penting yang mempengaruhi implementasi kebijakan publik. Komunikasi sangat menentukan keberhasilan pencapaian tujuan dari implementasi kebijakan publik. Terdapat tiga indikator yang dapat digunakan dalam mengukur keberhasilan variabel tersebut yaitu: transmisi, kejelasan dan konsistensi.

Berikut adalah data pelaksanaan sosialisasi dan pelayanan keliling di Desa Lumindai:

Tabel 3.1

Data Pelaksanaan Sosialisasi dan Pelayanan Keliling di Desa Lumindai

\begin{tabular}{|c|c|c|c|}
\hline NO & $\begin{array}{c}\text { JENIS } \\
\text { PELAYANAN }\end{array}$ & $\begin{array}{c}\text { TAHUN } \\
\text { PELAKSANAA } \\
\mathrm{N}\end{array}$ & KET \\
\hline 1 & $\begin{array}{l}\text { Sosialisasi } \\
\text { Program GISA }\end{array}$ & \multirow{3}{*}{2018} & \\
\hline & $\begin{array}{l}\text { Pelayanan } \\
\text { Keliling }\end{array}$ & & \\
\hline 2 & $\begin{array}{ll}(\text { Kartu } & \text { Keluarga } \\
\text { dan } & \text { Akta } \\
\text { Kelahiran) } & \end{array}$ & & \\
\hline 3 & $\begin{array}{l}\text { Sosialisasi } \\
\text { Program GISA } \\
\end{array}$ & \multirow{3}{*}{2019} & \\
\hline \multirow[b]{2}{*}{4} & $\begin{array}{l}\text { Pelayanan } \\
\text { Keliling }\end{array}$ & & \\
\hline & \begin{tabular}{|lr} 
Kartu & Keluarga \\
dan & Akta \\
Kelahiran) & \\
\end{tabular} & & \\
\hline \multirow{4}{*}{5} & $\begin{array}{l}\text { Pelayanan } \\
\text { Keliling }\end{array}$ & \multirow{4}{*}{2020} & \\
\hline & (Perekaman & & \\
\hline & \begin{tabular}{|ll} 
KTP, & Kartu \\
Keluarga & \\
\end{tabular} & & \\
\hline & $\begin{array}{l}\text { dan Dokumen } \\
\text { lainnya) }\end{array}$ & & \\
\hline
\end{tabular}

Sumber: Kantor Desa Lumindai

Dari tabel diatas hasil yang dicapai selama pelaksanaan sosialisasi Program Gerakan Indonesia Sadar Administrasi Kependudukan (GISA) dan Pelayanan Keliling masih belum optimal, belum $100 \%$ pencapaian target kepengurusan dokumen kependudukan, seperti yang terlihat pada table berikut dibawah ini:

Tabel 3.2

Pencapaian Target Kepengurusan Dokumen Kependudukan di Desa Lumindai

\begin{tabular}{|c|c|c|c|c|c|c|}
\hline \multirow{2}{*}{$\begin{array}{l}\mathrm{N} \\
\mathrm{O}\end{array}$} & \multirow{2}{*}{$\begin{array}{c}\text { URAIA } \\
\mathrm{N}\end{array}$} & \multicolumn{2}{|c|}{$\begin{array}{l}\text { DATA DI } \\
\text { DKB } \\
\text { SEMESTER } \\
\text { I Tahun } \\
2020\end{array}$} & \multicolumn{2}{|c|}{$\begin{array}{c}\text { DATA DI } \\
\text { DKB } \\
\text { SEMESTER } \\
\text { II Tahun } \\
2020\end{array}$} & $\begin{array}{c}\mathrm{KE} \\
\mathrm{T}\end{array}$ \\
\hline & & $\begin{array}{c}\text { JUML } \\
\text { AH } \\
\text { ORA } \\
\text { NG }\end{array}$ & $\%$ & $\begin{array}{c}\text { JUML } \\
\text { AH } \\
\text { ORA } \\
\text { NG }\end{array}$ & $\%$ & \\
\hline 1 & \begin{tabular}{|l} 
Yang \\
belum \\
memilik \\
i Akta \\
Kelahira \\
n \\
\end{tabular} & 1168 & $\begin{array}{l}41.1 \\
4 \%\end{array}$ & 1078 & $\begin{array}{l}37.9 \\
7 \%\end{array}$ & \\
\hline 2 & $\begin{array}{l}\text { Yang } \\
\text { belum } \\
\text { memilik } \\
\text { i KIA } \\
\end{array}$ & 607 & $\begin{array}{l}70.1 \\
7 \%\end{array}$ & 439 & $\begin{array}{l}50.7 \\
5 \%\end{array}$ & \\
\hline 3 & \begin{tabular}{|l} 
Yang \\
Belum \\
Upgrade \\
Kartu \\
Keluarg \\
a \\
\end{tabular} & 307 & $\begin{array}{l}38.0 \\
0 \%\end{array}$ & 205 & $\begin{array}{l}25.3 \\
7 \%\end{array}$ & \\
\hline 4 & \begin{tabular}{|l} 
Yang \\
Belu \\
Memilik \\
i KTP \\
\end{tabular} & 119 & $\begin{array}{l}6.03 \\
\%\end{array}$ & 88 & $\begin{array}{l}4.46 \\
\%\end{array}$ & \\
\hline
\end{tabular}

Sumber: DKB Semester II Tahun 2020

Dari tabel diatas, Program Gerakan Indonesia Sadar Administrasi Kependudukan GISA ini tidak hanya dilaksanakan oleh pelaksana program saja tetapi juga sangat dibutuhkan kontribusi dari sasaran program tersebut yaitu masyarakat. Untuk mencapai target yang maksimal segala usaha dan upaya sudah dilakukan oleh pemerintahan desa dan instansi terkait namun disini sangat dibutuhkan kontribusi 
masyarakat sebagai sasaran dari program ini agar dapat dilaksanakan dengan baik.

\section{b. Sumber Daya}

Sumber daya diposisikan sebagai input dalam organisasi yang mempunyai implikasi yang bersifat ekonomis dan teknologis. Ini dapat dibuktikan dari indikator-indikator yang digunakan untuk melihat sejauh mana sumber daya mempengaruhi implementasi kebijakan tersebut. Ada empat point dari faktor sumber daya yang mencakup keberhasilan suatu implementasi yaitu sumber daya manusia, anggaran, fasilitas dan informasi dan kewenangan. Sumber daya manusia yang ada di Desa Lumindai, dilihat dari segi pendidikan dari perangkat itu sendiri tingkat pendidikannya sudah diatas rata-rata yaitu SLTA dan dibilang cukup kompeten dan handal dalam pelaksanaan program tersebut. Berikut ini data pendidikan perangkat Desa Lumindai tergambar dari 3.3 dibawah ini.

Tabel 3.3

Data Pendidikan Perangkat di Lingkup Pemerintahan Desa Lumindai

\begin{tabular}{|l|l|c|c|l|}
\hline \multirow{2}{*}{ No } & \multirow{2}{*}{$\begin{array}{c}\text { TINGKAT } \\
\text { PENDIDIK } \\
\text { AN }\end{array}$} & \multicolumn{2}{|c|}{$\begin{array}{c}\text { JENIS } \\
\text { KELAMI }\end{array}$} & \multicolumn{2}{c|}{$\begin{array}{c}\text { JENIS } \\
\text { KEPEGAWAI } \\
\end{array}$} & \multicolumn{2}{|c|}{\begin{tabular}{c} 
AN \\
\cline { 3 - 4 }
\end{tabular}} & L & P & \\
\hline 1 & SMA & 8 & 4 & Kontrak \\
\hline 2 & D3 & 2 & 3 & Kontrak \\
\hline 3 & S1 & 2 & & Kontrak \\
\hline
\end{tabular}

Dilihat dari tabel diatas dapat kita analisa bahwa dari 19 orang total perangkat desa terdiri dari tamatan S1 sebanyak 2 orang dengan persentase $10,53 \%$, tamatan D3 sebanyak 3 orang dengan persentase $15,79 \%$, dan tamatan SLTA sebanyak 73,68\%. Dengan demikian sumber daya manusia di kalangan pemerintah Desa Lumindai dari segi pendidikan cukup memadai. Dan berikut adalah data pendidikan masyarakat Desa Lumindai seperti yang terlihat pada tabel 3.4 dibawah ini:

]
Tabel 3.4

Data Pendidikan Masyarakat Desa Lumindai

\begin{tabular}{|c|c|c|c|}
\hline NO & $\begin{array}{c}\text { TINGKAT } \\
\text { PENDIDIKAN }\end{array}$ & $\begin{array}{c}\text { JUMLA } \\
\text { H } \\
\text { (ORAN } \\
\text { G) }\end{array}$ & KET \\
\hline 1 & Belum Sekolah & 353 & \\
\hline 2 & Tidak Tamat SD & 784 & \\
\hline 3 & Sedang Sekolah SD & 401 & \\
\hline 4 & Tamat SD & 758 & \\
\hline 5 & $\begin{array}{l}\text { Sedang dan Tamat } \\
\text { SLTP }\end{array}$ & 213 & \\
\hline 6 & $\begin{array}{l}\text { Sedang dan Tamat } \\
\text { SLTA }\end{array}$ & 249 & \\
\hline 7 & Tamat D1/D2 & 2 & \\
\hline 8 & Tamat D3 & 13 & \\
\hline 9 & Tamat S1 & 66 & \\
\hline \multicolumn{2}{|r|}{ Total } & 2839 & \\
\hline
\end{tabular}

Sumber: Kantor Desa Lumindai

Dilihat dari table diatas dapat di analisa bahwa dari 2.839 Orang terdiri dari 353 orang belum sekolah dengan persentase $12,43 \%$, yang tidak tamat SD sebanyak 784 orang dengan persentase $27,62 \%$, yang sedang sekolah SD sebanyak 401 orang dengan persentase $14,12 \%$, yang tamat SD sebanyak 758 dengan persentase $26,70 \%$, yang sedang dan tamat SLTP sebanyak 213 orang dengan persentase $7,50 \%$, yang sedang dan tamat SLTA sebanyak 249 orang dengan persentase $8,77 \%$, tamat D1/D2 sebanyak 2 orang dengan persentasenya $0,07 \%$, tamat D3 sebanyak 13 orang dengan persentasenya $0,46 \%$, dan yang tamatan S1 sebanyak 66 orang dengan persentasenya 2,32\%. Dari analisis tersebut bisa disimpulkan bahwa sumber daya manusia dari segi pendidikan masyarakat Desa Lumindai masih rendah. Untuk bisa mengimplementasikan program GISA ini dengan baik di Desa Lumindai perlu peningkatan SDM bagi masyarakat Desa Lumindai seperti pemerintah memberikan sosialisasi terkait Program GISA.

\section{c. Disposisi (Disposition)}

Seorang staf pada dasarnya aset yang harus dikembangkan oleh pimpinan, mengingat seorang pimpinan sebagai atasan staf itu sendiri memiliki berbagai tugas yang sangat berat. Oleh karenanya pimpinan harus mampu mengelola organisasi melalui rentang kendali dalam pelaksanaan pekerjaan. Artinya pimpinan harus 
mampu memberdayakan staf lainnya dalam rangka mencapai tujuan yang ditetapkan. Mengingat peran seorang staf yang sangat besar dan dibutuhkan maka seorang pimpinan harus bisa mengarahkan staf sesuai dengan tugas masing-masing agar dapat berjalan secara efektif dan efisien.

\section{d. Struktur Birokrasi}

Birokrasi merupakan salah satu institusi secara keseluruhan menjadi pelaksana kegiatan, keberadaan birokrasi tidak hanya dalam struktur pemerintah, tetapi juga ada dalam organisasiorganisasi swasta, institusi pendidikan dan sebagainya. Implementasi kebijakan yang bersifat komplek menuntut adanya kerjasama banyak pihak. Ketika struktur birokrasi tidak kondusif terhadap implemetasi suatu kebijakan, maka hal ini akan menyebabkan ketidak efektifan dan menghambat jalanya pelaksanaan kebijakan. Untuk mengkaji struktur birokrasi ada dua yang paling utama yaitu Standar Operasional Prosedur (SOP) dan fragmentasi.

Berikut peneliti melakukan analisis mengenai sejauh mana pelaksanaan SOP dalam pelaksanaan Program GISA ini. Ada beberapa masyarakat yang mendapat perlakuan pelayanan yang baik dan ada beberapa yang kurang baik. Ketika di SOP penertiban dokumen kependudukan hanya butuh beberapa hari namun ada yang melebihi dari waktu yang ditentukan dan ada pula yang belum sampai harinya sudah siap terutama yang memiliki koneksi. Berikut peneliti lampirkan SOP di lingkup kerja Dinas Kependudukan dan Pencatatan Sipil Kota Sawahlunto seperti yang terlihat pada table 3.5 dibawah ini:

Tabel 3.5

SOP Penerbitan Dokumen Kependudukan

\begin{tabular}{|c|l|ll|l|}
\hline $\begin{array}{c}\text { N } \\
\mathrm{O}\end{array}$ & \multicolumn{1}{|c|}{$\begin{array}{l}\text { JENIS } \\
\text { PELANA }\end{array}$} & \multicolumn{2}{|c|}{$\begin{array}{l}\text { JANGKA } \\
\text { WAKTU }\end{array}$} & \multicolumn{2}{|c|}{ KET } \\
\hline 1 & $\begin{array}{l}\text { Akta } \\
\text { Kelahiran }\end{array}$ & $\begin{array}{l}3-4 \quad \text { Hari } \\
\text { Kerja }\end{array}$ & \\
\hline 2 & $\begin{array}{l}\text { Kartu } \\
\text { Keluarga }\end{array}$ & $\begin{array}{l}3-4 \quad \text { Hari } \\
\text { Kerja }\end{array}$ & \\
\hline 3 & $\begin{array}{l}\text { Kartu Tanda } \\
\text { Penduduk }\end{array}$ & 1 Hari Kerja & $\begin{array}{l}\text { Tergantun } \\
\text { g Kondisi } \\
\text { Jaringan }\end{array}$ \\
\hline 4 & $\begin{array}{l}\text { Akta } \\
\text { Kematian }\end{array}$ & $\begin{array}{l}\text { 3-4 Hari } \\
\text { Kerja }\end{array}$ & \\
\hline
\end{tabular}

\begin{tabular}{|c|l|l|l|}
5 & $\begin{array}{l}\text { Kartu } \\
\text { Identitas } \\
\text { Anak }\end{array}$ & 1 Hari Kerja & $\begin{array}{l}\text { Tergantun } \\
\text { g Kondisi } \\
\text { Jaringan }\end{array}$ \\
\hline 6 & Surat Pindah & $\begin{array}{l}3-4 \quad \text { Hari } \\
\text { Kerja }\end{array}$ & \\
\hline
\end{tabular}

Sumber: Dinas Kependudukan dan Pencatatan Sipil Kota Sawahlunto

\section{Kendala-Kendala yang Ditemui pada Implementasi Program Gerakan Indonesia Sadar Administrasi Kependudukan GISA di Desa Lumindai Kota Sawahlunto}

Dalam pelaksanaan program GISA di Desa Lumindai kota Sawahlunto tentunya tidak selalu mudah dan berjalan mulus saja, apalagi didalam pelayanan publik tentu tidak terlepas dari kendala-kendala yang ditemui dilapangan.

\section{a. Sarana dan Prasarana yang Kurang Memadai}

Pentingnya sarana dan prasarana di dalam pelaksanaan suatu program adalah untuk menunjang proses dalam pelaksanaan program tersebut agar berjalan dengan efektif. Salah satu faktor kelemahan atau gagalnya suatu program adalah karena kurangnya penganggaran dari pusat dan daerah baik itu dalam bentuk fisik dan non fisik.

Sarana dan prasarana mempunyai tujuan yang sama, yaitu mencapai hasil yang diharapkan sesuai dengan tujuan yakni antara lain mempercepat proses pelaksanaan pekerjaan sehingga mampu menghemat waktu, meningkatkan produktivitas barang maupun jasa, menimbulkan rasa kenyamanan serta rasa puas bagi pihak-pihak yang berkepentingan.

\section{b. Sumber Daya Aparatur}

Memberikan pelayanan yang maksimal kepada masyarakat sangat dibutuhkan aparatur pemerintah yang memadai. Jumlah pegawai yang ada di seksi pelayanan administrasi kependudukan ada 2 orang, terdiri dari 1 orang kepala seksi pemerintahan, 1 orang petugas registrasi. Sedangkan di desa pekerjaannya tidak hanya melayani masyarakat saja tapi juga memiliki tugas pokok lainnya yang harus dilaksanakan. Dengan keterbatasan jumlah pegawai dibagian pelayanan administrasi kependudukan sehingga dapat menghambat kerja pelayanan kepada masyarakat dan target dalam mencanangkan program GISA, tidak terwujud. 


\section{c. Kurangnya Kesadaran Masyarakat}

Salah satu faktor yang turut mempengaruhi pelaksanaan tugas pelayanan administrasi kependudukan pemerintah Desa Lumindai adalah faktor kesadaran masyarakat. Kesadaran masyarakat dimaksudkan ialah kesadaran untuk mempersiapkan segala yang menjadi persyaratan untuk melakukan suatu urusan.

\section{Upaya Mengatasi Kendala-Kendala yang} Ditemui pada Implementasi Program Gerakan Indonesia Sadar Administrasi Kependudukan GISA di Desa Lumindai Kota Sawahlunto

Adapun upaya-upaya yang telah dilakukan Kepala Desa Lumindai untuk mengatasi kendala antara lain membeli 1 unit Handphone dan saat ini lagi mengupayakan memasang jaringan wifi yang besar sehingga dapat meningkatan layanan administrasi kependudukan secara online melalui email ataupun melalui website.

\section{CONCLUSION}

Berdasarkan hasil pemaparan dan pembahasan maka peneliti mendapatkan kesimpulan bahwa Implementasi Program GISA di Desa Lumindai belum optimal. Beberapa faktor yang menjadi penghambat antara lain:

1. Dalam pelaksanaan Program Gerakan Indonesia Sadar Administrasi Kependudukan (GISA) di Desa Lumindai melalui sosialisasi tidak semua masyarakat bisa menerimanya karena kurangnya SDM dan kurangnya kesadaran dalam mengurus dokumen maka perlu dilakukan dengan cara mengajak seperti turun langsung kelapangan, mendatangi ke rumah. Cara ini bisa dibilang efektif untuk menjalankan program Gerakan Indonesia Sadar Administrasi Kependudukan (GISA) tersebut.
Sumber daya aparatur di atasi dengan diperbantukannya perangkat lain yang tidak terlalu sibuk dengan kegiatannya atau diberikan tugas kepala dusun untuk stay dikantor lorang perhari sehingga petugas yang bertugas tidak terlalu kewalahan.

Kurangnya kesadaran masyarakat, masyarakat yang minim sumber daya tentu berpengaruh terhadap pola pikirnya sehingga sebagian mereka mengganggap Dokumen Kependudukan itu tidak penting, untuk mengatasi kurangnya kesadaran masyarakat dalam mengurus dokumen kependudukan, dilakukan dengan cara menjemput bola atau melaksanakan pelayanan dari rumah kerumah. Peneliti menganalisa bahwa untuk mengatasi kurangnya kesadaran masyarakat dalam mengurus dokumen dilakukan dengan memberikan pelayananan prima dan sering diadakannya pelayanan keliling.

2. Kurangnya personil dapat menghambat pelaksanaan Program Gerakan Indonesia Sadar Administrasi Kependudukan (GISA) di Desa Lumindai, mengingat kondisi penduduk Desa Lumindai yang ribuan penduduk tidak bisa hanya dikerjakan oleh 2 orang staff saja, hal ini menyangkut tugas dan perannya sebagai staff jadi tidak maksimal.

Pelayanan yang belum sesuai SOP hendaknya dibahas dan di kaji lebih lanjut agar tidak menimbulkan pembicaraan di kalangan masyarakat yang menyebabkan kesalahan tertumpu kepada pegawai atau pelaksana program, padahal tidak selalu menjadi kesalahan pegawai, kesalahan bisa terjadi karena masyarakat itu sendiri yang memperlambatnya. 


\section{Bibliography}

[1]Agustinus. 2006. Politik dan Kebijakan Publik. Bandung. AIPI.

[2]Andi, Prastowo. 2010. Menguasai Teknikteknik Koleksi Data Penelitian Kualitatif. Yogyakarta. DIVA Press.

[3]Dunn. 2003. Pengantar Analisis dan Kebijakan Publik. Yogyakarta. Gajah Madah University.

[4]Eyestone, Robert. 2008. Kebijakan Publik. Jakarta. Bumi Aksara.

[5]Kencana, Syafiie Inu. 2008. Implementasi Kebijakan. Jakarta. Bumi Aksara.

[6]Moleong, Lexy J. 1995. Metodologi Penelitian Kualitatif. Bandung. PT. Remaja Rosdakarya.

[7]Sugiyono. 2009. Metode Penelitian Kuantitatif Kualitatif dan R\&D. Bandung. Alfabeta.

[8]Susilo. 2013. Implementasi Kebijakan Publik. Yogyakarta. Pustaka Belajar.

[9]Supromo, Bambang. 2013. Metodologi Penelitian. Yogyakarta. BPFE.
[10]Umar, Husein. 2002. Metode Riset Bisnis. Jakarta. PT. Grame Pustaka Utama.

[11]Widodo. 2010. Analisis Kebijakan Publik. Malang. Bayu Media

[12]Widavisky, Pressman. Implementasi Kebijakan Publik. Yogyakarta. Pustaka Belajar.

[13]Winarno. 2005. Kebijakan dan Proses Kebijakan Publik. Yogyakarta. Media Pressindo.

[14]Woll. 2003. Analisis Kebijakan Publik. Bandung. Alfabeta.

[15]Instruksi Menteri Dalam Negeri Republik Indonesia Nomor 470/837/SJ tentang Gerakan Indonesia Sadar Administrasi Kependudukan.

[16]Undang-undang Republik Indonesia Nomor 24 Tahun 2013 tentang Perubahan Atas Undang-undang Nomor 23 Tahun 2006 tentang Administrasi Kependudukan. 